\title{
The Effects of Electron Beam Melting on the Microstructure and Mechanical Properties of Ti-6Al-4V and Gamma-TiAl
}

\author{
Tait McLouth ${ }^{1}$, Yuan-Wei Chang ${ }^{1}$, John Wooten $^{2}$, Jenn-Ming Yang ${ }^{1}$ \\ 1. Department of Materials Science and Engineering, University of California, Los Angeles, U.S.A. \\ 2. CalRam Inc., Simi Valley, CA, U.S.A.
}

Titanium alloys have been used extensively in the aerospace and biomedical industries due to their high strength to weight ratios, elevated temperature mechanical properties, excellent biocompatibility, and good corrosion resistance [1-4]. Alloys, such as Ti-6Al-4V (Ti-6-4) can be used for replacement hip joints, knee joints, and bone plates because of the aforementioned properties. Titanium-aluminum intermetallic alloys such as $\gamma$-TiAl are attractive for high temperature turbine engine components because of their good thermal stability and low density [5]. Recently, both of these alloys have been manufactured with additive manufacturing (AM) because traditional methods such as casting and forging present problems and limitations [5]. AM provides more design flexibility for titanium alloys, a great benefit when considering the complexity of certain parts made for biomedical implants or jet engines. Electron beam melting (EBM) is a powder processing AM technique that produces fully net shaped parts from a bed of powder, and it is the main focus of this study.

In this research, the microstructure and mechanical properties of both Ti-6-4 and $\gamma$-TiAl were studied before and after the EBM process. X-Ray diffraction (XRD), nanoindentation, and micropillar compression were performed to gain an understanding of the effects of the EBM manufacturing process. Microstructural evaluation was performed with the use of a scanning electron microscope (SEM). Figure 1 (a)(b) shows the microstructure of Ti-6-4 and $\gamma$-TiAl, respectively. Both alloys form a fine lamellar microstructure of alternating phases; these needle like Widmanstätten structures serve to strengthen the alloys by reducing crack propagation through the material.

Micropillars prepared by focused ion beam (FIB) milling were compressed by a nanoindenter in order to gather the yield strength and Young's modulus. Stress/strain curves for micropillars are shown in Figure 2(a) and (b) for Ti-64 and $\gamma$-TiAl, respectively. Tabulated values for the experimentally calculated compressive yield strengths, hardnesses, and Young's Moduli are shown in Table 1. From Table 1, it is clear that the EBM manufacturing process has a positive effect on the mechanical properties of Ti-6-4 and $\gamma$-TiAl. Compared to a cast sample of Ti-6-4 that underwent identical testing, the EBM sample displayed yield strengths that were $39 \%$ higher on average. This is due to the microstructure that is formed upon cooling. Specifically for Ti-6-4, the $\beta$ phase that forms enhances the mechanical properties, as it has a higher strength than the $\alpha$ phase and also acts as a strengthening phase [6]. Referring to Figure 1 , very fine spacing of the lighter $\beta$ phase can be observed. The mechanical properties found for $\gamma$-TiAl agree well with calculated and experimental values from the literature with a Young's modulus of $179 \pm$ $5 \mathrm{GPa}$.

From this research it can be concluded that the manufacturing process plays a significant role in the final mechanical behavior of a material. In the case of Ti alloys, there seems to be a strengthening effect due to the faster cooling rate and favorable microstructure that forms as a result. Future work to be performed will involve a TEM analysis of the deformation mechanisms of both materials as well as an analysis of the base powder from which EBM samples are produced. 
References:

[1] Y. Okazaki, S. Rao, Y. Ito, T. Tateishi, "Corrosion resistance, mechanical properties, corrosion fatigue strength and cytocompatibility of new Ti alloys without Al and V," Biomaterials 19 (1998) 1197-1215.

[2] Y. Okazaki, E. Nishimura, H. Nakada, K. Kobayashi, "Surface analysis of Ti-15Zr-4Nb-4Ta alloy after implantation in rat tibia," Biomaterials 22 (2001) 599-607.

[3] E. Eisenbarth, D. Velton, M. Müller, R. Thull, J. Breme, "Biocompatibility of beta-stabilizing elements of titanium alloys," Biomaterials 25 (2004) 5705-13.

[4] M. Niinomi, "Biologically and Mechanically Biocompatible Titanium Alloys," Mater. Trans. 49 (2008) 2170-8.

[5] S. F. Franzen, Joakim Karlsson, " $\gamma$-Titanium Aluminide Manufactured by Electron Beam Melting," Sanna Fager Franzen, Joakim Karlsson (2010).

[6] William F. Smith, "Structure and Properties of Engineering Alloys", Second Ed. (New York, NY: McGraw-Hill, 1993) 201-245.

(a)

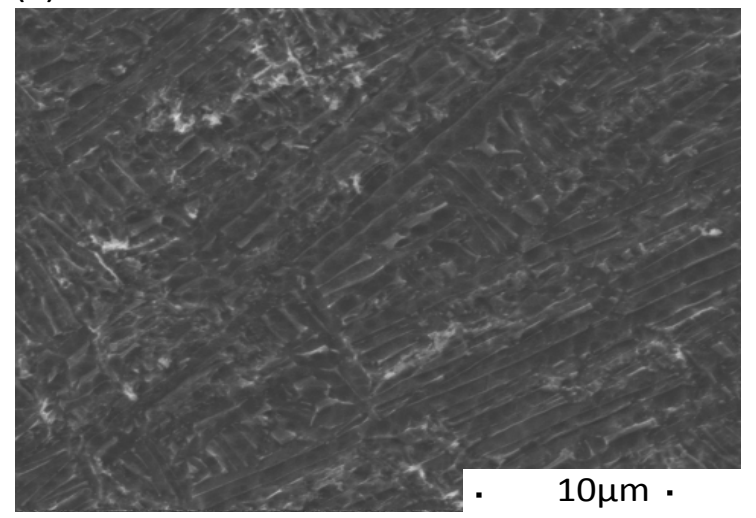

(b)

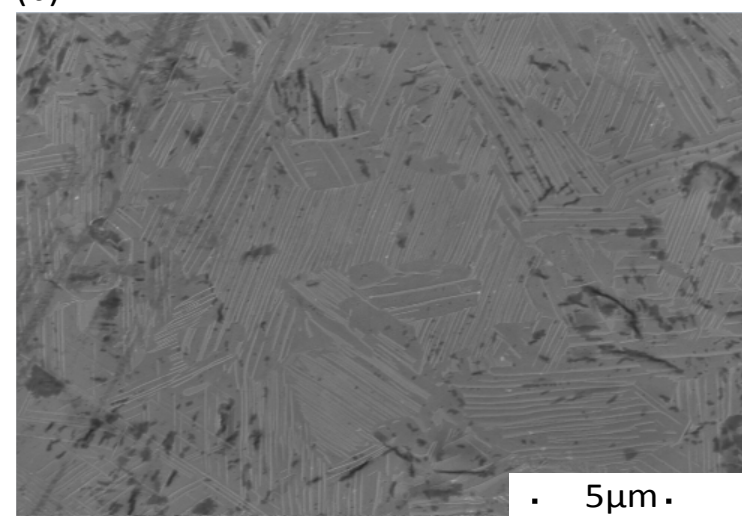

Figure 1: SEM images of microstructures for (a) Ti-6-4 showing the $\mathrm{V}$ rich $\beta$ phase (lighter) and Al rich $\alpha$ phase (darker) and (b) $\gamma$-TiAl showing the $\alpha_{2}-\mathrm{Ti}_{3} \mathrm{Al}$ phase (lighter) and $\gamma$-TiAl phase (darker)

(a)

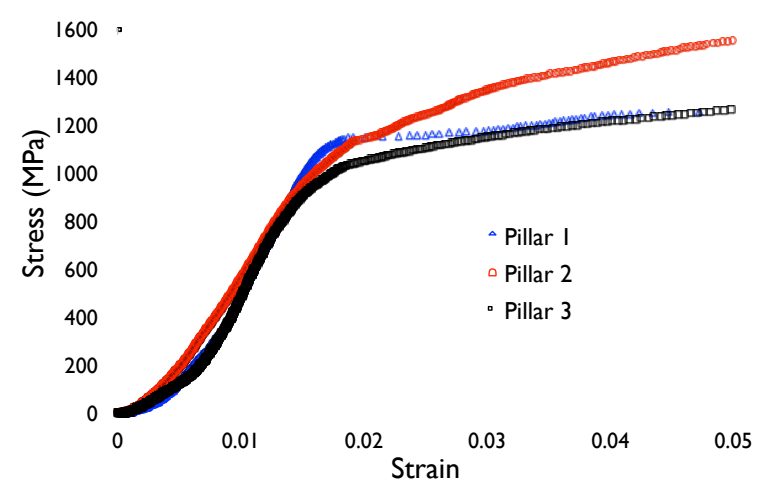

(b)

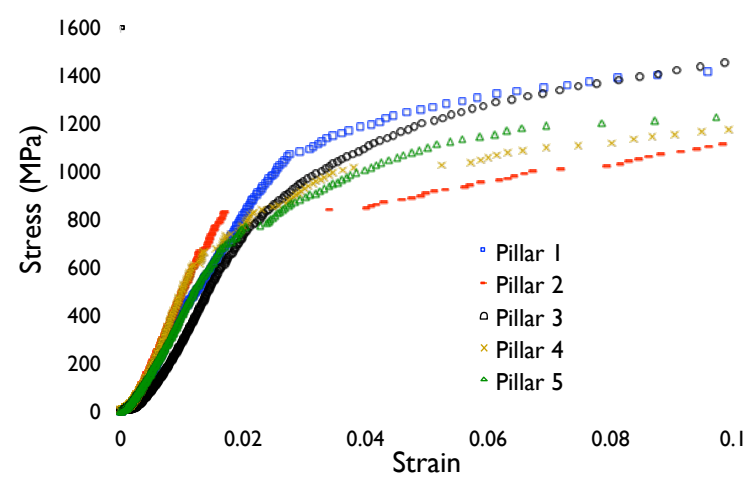

Figure 2: Micro-compressive stress-strain curves of (a) Ti-6-4 and (b) $\gamma$-TiAl

\begin{tabular}{|c|c|c|c|}
\hline Material & Yield Strength & Young's Modulus & Hardness \\
\hline EBM Ti-6-4 & $1135 \pm 12 \mathrm{MPa}$ & $114 \pm 6 \mathrm{GPa}$ & $4.5 \pm 0.3 \mathrm{GPa}$ \\
\hline Cast Ti-6-4 & $812 \pm 26 \mathrm{MPa}$ & $116 \pm 2 \mathrm{GPa}$ & $4.1 \pm 0.2 \mathrm{GPa}$ \\
\hline EBM $\boldsymbol{\gamma}$-TiAl & $620 \pm 21 \mathrm{MPa}$ & $179 \pm 5 \mathrm{GPa}$ & $5.3 \pm 0.2 \mathrm{GPa}$ \\
\hline
\end{tabular}

Table 1: Mechanical properties of tested samples 